\title{
Potencialização da Aprendizagem Autorregulada de Bolsistas do PIBID/UFPel do curso de Licenciatura em Matemática através de Oficinas Pedagógicas
}

\author{
Enhancement of Fellows of Self-Regulated Learning of PIBID/UFPel's \\ Degree in Mathematics through Pedagogical Workshops
}

\author{
Amanda Pranke* \\ Lourdes Maria Bragagnolo Frison ${ }^{* *}$
}

\begin{abstract}
Resumo
Este artigo apresenta a síntese de uma pesquisa qualitativa do tipo estudo de caso, que analisou se as oficinas desenvolvidas no Projeto Institucional de Bolsa de Iniciação à Docência/PIBID, do curso de Licenciatura em Matemática, da Universidade Federal de Pelotas/UFPel, promoveram a aprendizagem autorregulada das bolsistas de Matemática, qualificando seus processos de aprender e ensinar. Os dados coletados advieram da análise documental realizada a partir do projeto, do relatório das oficinas de Matemática desenvolvidas e das entrevistas semiestruturadas realizadas com três bolsistas de Matemática, que atuaram nas oficinas. Os dados foram submetidos à análise de conteúdo e dela emergiram as seguintes categorias: a) planejamento; b) execução; c) avaliação das oficinas de Matemática realizadas em uma ação colaborativa. Pelos dados analisados, inferiu-se que as bolsistas desenvolveram ações que revelaram sua capacidade de organizar, planejar e programar tarefas a serem realizadas dentro de um prazo estabelecido.
\end{abstract}

Palavras-chave: PIBID/UFPel. Oficinas de Matemática. Autorregulação da Aprendizagem.

\begin{abstract}
We conducted a qualitative case study type, trying to analyze whether the workshops developed in the Institutional Scholarship Project Initiation to Teaching/PIBID, the degree course in Mathematics of Federal University of Pelotas/UFPel, promoted self-regulated learning of fellows mathematics, describing their processes of learning and teaching. The collected data were derived from a document analysis performed from the project and the report of workshops developed mathematics and also conducted semi-structured interviews with three fellows who worked on math workshops. The data were subjected to content analysis and it emerged the following categories: a) planning b) execution c) evaluation of math workshops conducted in a collaborative

* Doutoranda em Educação pela Universidade Federal de Pelotas (UFPel). Integrante do Grupo de Estudo e Pesquisa da Aprendizagem Autorregulada/GEPAAR. Professora Pesquisadora Orientadora de Estágios do curso de Licenciatura em Matemática à Distância da UFPel, Pelotas/RS, Brasil. Endereço para correspondência: Rua Ismael Simões Lopes no 168, Bairro Fragata, Pelotas/RS, Brasil, CEP: 96.030.670. Endereço eletrônico: amandapranke@ymail.com.

** Doutora em Educação pela Pontifícia Universidade Católica do Rio Grande do Sul (PUC-RS). Professora do Programa de Pós-Graduação em Educação, da Faculdade de Educação (UFPel). Líder do Grupo de Estudo e Aprendizagem Autorregulada/GEPAAR, Pelotas/RS, Brasil. Endereço para correspondência: Rua Engenheiro Rodolfo Ahrons $\mathrm{n}^{\circ}$ 285, Bairro Intercap, Porto Alegre/RS, Brasil, CEP 91.530.320. Endereço eletrônico: lfrison@terra.com.br.
\end{abstract}


action. Analyzing the data, we inferred that the scholars developed actions that revealed the ability to organize, plan, and schedule tasks to be performed within the given deadline.

Keywords: PIBID/UFPel. Workshops Mathematics. Self-Regulation of Learning.

\section{Introdução}

O PIBID (Programa Institucional de Bolsas de Iniciação à Docência) é um programa do Ministério da Educação gerenciado pela Coordenação de Aperfeiçoamento de Pessoal do Ensino Superior (CAPES). Ele tem como objetivo apoiar a formação de alunos dos cursos de licenciatura presenciais das universidades públicas, comunitárias e privadas. Esse programa vem se destacando pelo crescimento nacional de sua importância, o que justifica e infere a realização de pesquisas em seu entorno. O projeto apresenta potencialidades para pesquisas que investiguem sua contribuição ou impacto tanto na formação de professores, como na escola.

Rosa (2010) organizou um caderno de resumos elaborado pelos bolsistas das diferentes áreas de conhecimento em parceria com professores, o qual foi publicado pela Universidade Federal de Mato Grosso do Sul. Nesse caderno, os universitários registraram as atividades e oficinas realizadas na escola e refletiram sobre elas. Tais atividade e oficinas oportunizaram contribuições significativas à sua formação docente, como a exploração do contexto escolar, a aproximação entre teoria e prática, o domínio de conteúdo. Eles destacaram o quanto o PIBID enriqueceu a construção do conhecimento sobre ser professor.

Referindo-se especialmente à área de Matemática, Souza et al. (2010) apresentam, em sua pesquisa, as atividades desenvolvidas no PIBID, na Universidade Federal de Goiás, dentre elas, jogos e o uso de softwares no ensino de Matemática e discutem sua importância nos processos de ensino e aprendizagem. Os autores mostram que as tarefas desenvolvidas no projeto, além de motivar e despertar o interesse dos alunos para aprender, possibilitaram aos bolsistas vivenciarem experiências teórico-práticas que contribuem com a formação inicial e dão respaldo ao trabalho docente.

$\mathrm{O}_{\text {PIBID }}{ }^{1}$ realizado na UFPel foi pioneiro em assumir a importante tarefa de envolver bolsistas/futuros professores, alunos e professores das diferentes áreas de conhecimento, com o objetivo de criar novas oportunidades de aprendizagem. A presente investigação não só

\footnotetext{
${ }^{1}$ Ao aparecer a sigla PIBID, fica implícito que ela se refere ao primeiro Programa do PIBID realizado na Universidade Federal de Pelotas - UFPel. Este projeto foi desenvolvido de fevereiro de 2009 a fevereiro de 2011. Atualmente o PIBID abrange todos os cursos de Licenciaturas da UFPel, totalizando 16 cursos. Ele é um programa financiado pela CAPES.
} 
descreve o trabalho realizado, mas também analisa seus resultados, a fim de evidenciar se, por meio dele, houve melhoria ou não nos processos de ensino e de aprendizagem das bolsistas envolvidas.

Foi proposto, como objetivo geral para esta pesquisa, analisar se as oficinas desenvolvidas no PIBID promoveram a aprendizagem autorregulada das bolsistas do curso de licenciatura em Matemática, qualificando seus processos de aprender e ensinar.

\section{Um estudo sobre o construto da Autorregulação da Aprendizagem}

Uma das funções da escola é promover as competências dos alunos, para que eles possam gerir seus processos de aprendizagem e trilhar, com autonomia crescente, seu percurso acadêmico, dispondo de ferramentas intelectuais e sociais que lhes permitam a aprendizagem ao longo da vida. Aprender para ensinar não é tarefa fácil, implica que os professores repensem suas práticas pedagógicas e contribuam, de maneira significativa, com a aprendizagem de seus alunos. Essas questões remetem a pensar nas dificuldades que, normalmente, são encontradas no ensino e na aprendizagem da Matemática.

Os futuros professores de Matemática, como explica D'Ambrosio (2005), precisam aprender e ensinar os alunos a utilizarem a Matemática de forma contextualizada, para que reconheçam sua importância em qualquer tarefa do cotidiano. A Matemática é usualmente conceituada como a ciência das formas e dos números, das relações e das medidas. Suas características direcionam para a precisão, o rigor e a exatidão. Essa maneira de conceituar tal ciência fortalece a crença de que sua aprendizagem se dá através do acúmulo de fórmulas, de algoritmos e de muito treino (D'AMBROSIO, 1989). Os professores de Matemática precisam investir em estratégias autorregulatórias para que os alunos tenham maior conhecimento acerca das estratégias de aprendizagem e, através delas, encontrem formas para aprender, o que poderá promover autoconfiança, organização, concentração, possibilitando-lhes interagir em sala de aula. É preciso que os docentes tomem consciência de que ensinar Matemática é desenvolver o raciocínio lógico, estimular o pensamento independente, a criatividade, a reflexão, a capacidade de abstração na busca da internalização de saberes, propiciando aos alunos condições para resolver problemas (OLIVEIRA, 2007).

A autorregulação da aprendizagem é conceituada como um processo pessoal interno que oportuniza aos sujeitos criarem metas e desenvolverem estratégias para alcançarem a aprendizagem (VEIGA SIMÃO, 2002; 2004; 2004a; 2006; 2008; LOPES DA SILVA, 2004; ZIMMERMAN, 1998; 2000; ROSÁRIO, 2004; ROSÁRIO et al., 2006; 2008). Na 
autorregulação da aprendizagem, o professor assume o papel de organizador e mediador da aprendizagem e o aluno desempenha papel ativo, sendo capaz de elaborar seus próprios objetivos e estabelecer metas para ampliar conhecimentos.

A autorregulação da aprendizagem se refere a pensamentos, sentimentos e ações que são sistematicamente adaptados, sempre que necessário, para incrementar a motivação e a aprendizagem (ZIMMERMAN, 2000, 2002). No campo da educação, a autorregulação da aprendizagem compreende um amplo conjunto de processos e estratégias, tais como: estabelecimento de objetivos; organização e recuperação da informação aprendida; construção de um ambiente de trabalho que favoreça o rendimento acadêmico; gestão de tempo; procura da ajuda necessária (ROSÁRIO, NÚÑEZ; GONZÁLEZ-PIENDA, 2006a).

Zimmerman (1998) explana que a autorregulação da aprendizagem contempla três fases. A fase prévia refere-se a toda atividade preparatória que o sujeito faz, antes de iniciar a tarefa, ao gerar objetivos para seu estudo e o plano estratégico para sua realização. A segunda fase diz respeito à execução, que se relaciona com o desempenho do sujeito na realização da tarefa, envolve os processos que ocorrem durante o esforço de aprendizagem. A terceira fase refere-se à autorreflexão dos processos que ocorreram e que influenciaram os sujeitos no processo de aprendizagem.

A autorregulação da aprendizagem deve ser compreendida como um processo multidimensional (VEIGA SIMÃO, 2006), o qual envolve as seguintes dimensões: metacognitiva, motivacional, comportamental, contextual, pois cada um tem seu jeito e seu tempo de aprender, com base em suas vivências.

A utilização de estratégias de aprendizagem requer que o indivíduo seja capaz de refletir sobre os próprios processos mentais, o que pode ser conceituado como metacognição. A metacognição é compreendida como uma estratégia reguladora que perpassa todo o processo de aprendizagem, no qual os estudantes estabelecem metas que interagem com suas expectativas; desenvolvem estratégias para alcançá-las; criam condições para que a aprendizagem se efetive. Entende-se, pois, a metacognição como a capacidade do ser humano de planificar, compreender e avaliar tudo o que foi aprendido, ou seja, a capacidade de monitorizar e autorregular os processos cognitivos (FLAVELL, 1979).

Além da metacognição, a motivação é fator desencadeante para que o aluno autorregule a aprendizagem. No contexto escolar, ele se motiva para aprender se os conteúdos lhe fazem sentido. Assim, ele se mobiliza para buscar e pesquisar, aguçando sua curiosidade, tornando a aprendizagem ativa e dinâmica. A motivação, segundo Rosário et al. (2008), corresponde à energia para iniciar e manter uma ação, levando o indivíduo a persistir nela. 
A dimensão comportamental compreende a gestão do tempo e do esforço; a consciência e o controle do esforço, do tempo e da necessidade de ajuda; o aumento ou a redução do esforço; a persistência ou o abandono da tarefa; a procura de ajuda; a iniciativa para mudar determinado comportamento, quando julgado ineficaz ou insuficiente para atingir os objetivos pretendidos (VEIGA SIMÃO, 2008).

$\mathrm{O}$ ambiente de estudo deve ser propício à aprendizagem, portanto a análise do contexto é indispensável para que se promova a autorregulação (PINTRICH, 2000). Na sala de aula, o professor precisa criar situações de aprendizagem em que os alunos possam tomar as próprias decisões, expor suas ideias e justificativas, ou seja, ele deve criar possibilidades, no ambiente escolar, para que os alunos possam autorregular o aprender.

O processo de autorregulação da aprendizagem possui dois eixos principais: a capacidade de refletir sobre a ação e tomar consciência e a capacidade de controle sobre as competências de estudo, desde o estabelecimento de objetivos frente às tarefas escolares até a utilização de estratégias de aprendizagem. Nesse sentido, o papel do professor é conhecer e ensinar o conteúdo, mostrando estratégias possíveis para a aprendizagem, estimulando que o aluno reflita sobre suas escolhas e sobre o que foi discutido em aula. Isso promoverá a tomada de consciência e o controle sobre as ações a serem realizadas, ações que se constituem como estratégias de aprendizagem. Essas estratégias se referem à adoção de procedimentos para a realização de uma tarefa e podem ser escolhidas pelos alunos ou pelos professores com a intenção de alcançarem os objetivos de aprendizagem desejada (LOPES DA SILVA; SÁ, 1993).

É necessário que os professores atuem estrategicamente quando aprendem e quando ensinam, assim se torna possível o ensino de estratégias de aprendizagem. Para isso, os professores precisam analisar os próprios estilos de aprendizagem, avaliar sua compreensão, tomar consciência do que realmente é importante ensinar e de que maneira proceder para que o aluno aprenda conscientemente.

\section{Contextualização do Projeto PIBID e dos sujeitos de pesquisa}

As boas práticas pedagógicas requerem professores que invistam em estratégias que promovam a aprendizagem dos alunos e que reflitam sobre o que fazem, como fazem e por que as tarefas são propostas. Frente aos desafios colocados à tarefa do professor, compreende-se que, se a maioria dos professores conseguir elevar a qualidade da formação, o investimento e o retorno na formação inicial e continuada será ampliado. O Ministério da Educação tem se preocupado com essa realidade e, por isso, criou, em 2009, o Programa 
Institucional de Bolsa de Iniciação à Docência (PIBID), o qual se mantém até hoje.

O primeiro programa do PIBID, realizado na UFPel, contou com a participação de bolsistas dos cursos de licenciatura em Biologia, Física, Matemática e Química; professores e supervisores; docentes das escolas; coordenadores das diferentes áreas de ensino; docentes da UFPel; coordenação institucional, que responde pelo programa junto à UFPel e à CAPES. O Projeto foi realizado em quatro escolas públicas estaduais de Ensino Médio da cidade de Pelotas/RS, nas quais foram desenvolvidas atividades de monitoria e oficinas, bem como um projeto interdisciplinar. A presente pesquisa foi realizada com alunas do curso de licenciatura em Matemática que atuaram no Projeto, em uma das escolas envolvidas.

As bolsistas do curso de Matemática que atuaram neste Projeto, incluindo a pesquisadora - primeira autora deste texto, eram estudantes universitárias tendo em média 20 anos de idade. Antes de atuar no Projeto PIBID, não tinham nenhuma experiência com a docência na modalidade de ensino médio, apenas tinham realizado o estágio supervisionado no ensino fundamental. Ao ingressarem no PIBID, as bolsistas estavam na metade do curso de licenciatura em Matemática, ou seja, no quarto semestre letivo.

\section{Descrição das Oficinas de Matemática}

Analisou-se o trabalho desenvolvido nas quatro oficinas realizadas no projeto "Matemática Elementar: alicerce para um ensino de qualidade". Elas foram constituídas a partir das experiências realizadas nas monitorias, nas quais as bolsistas identificavam as principais dúvidas dos alunos e, em parceria com o coordenador de área, elaboravam as atividades. Estas foram baseadas no ensino experimental da Matemática, sendo trabalhados alguns conteúdos através de tarefas práticas. Para sua realização, foram utilizados materiais concretos, visando à contextualização e à aprendizagem dos conteúdos por parte dos alunos.

Cada oficina teve, em média, 40minutos de duração. Elas foram todas aplicadas a uma turma de 13 alunos de Ensino Médio, à noite, em novembro de 2009. Para a realização das oficinas, foi disponibilizado, na escola, um espaço de trabalho para os alunos. Com o aprofundamento e a contextualização de conteúdos, as bolsistas revisaram e (re)construíram oportunidades de aprendizagem em relação aos conteúdos de Matemática básica do Ensino Fundamental, especialmente relacionados a conceitos de raiz quadrada, frações, mínimo múltiplo comum (m.m.c.) e representação dos números na reta real.

A oficina "Uma Interpretação Geométrica para o Cálculo da Raiz Quadrada" consistiu em desenvolver o conceito de raiz quadrado, dando uma interpretação geométrica ao seu 
cálculo, através da construção de quadrados e retângulos, com a utilização do material dourado, e explorando a compreensão do conceito de raiz quadrada de um número real positivo, como a medida do lado do quadrado cuja área é igual ao número considerado.

Na oficina "Estudo de Frações" foram utilizadas tampinhas de garrafas para visualizar as frações de uma quantidade. As bolsistas explicaram as tarefas e os alunos trabalharam com conjuntos de tampinhas, dos quais foram destacando subconjuntos que representavam frações da quantidade recebida. Nesse processo, as bolsistas e os alunos anotavam os resultados encontrados, os quais foram utilizados para trabalhar com frações equivalentes, próprias e impróprias.

A oficina "M.M.C. Geométrico" consistiu em apresentar uma alternativa para o cálculo do m.m.c., utilizando noções básicas de geometria, tais como: figuras planas, base, altura e diagonal. Esses conhecimentos foram utilizados ao marcar um retângulo em uma folha quadriculada, cujas medidas dos lados eram os números para os quais se procurava o m.m.c. Então, partindo de um dos vértices do retângulo, as bolsistas explicaram e os alunos traçaram a diagonal de todos os quadrados até encontrar um lado do retângulo. Imaginando que cada lado tinha a propriedade de reflexão, eles desenharam a diagonal dos outros quadrados até encontrar outro lado do retângulo. Repetindo esse procedimento, as bolsistas disseram que estaria concluído no momento em que chegassem em outro vértice do retângulo. Para descobrir o valor do m.m.c., eles contaram o número de quadradinhos que tiveram suas diagonais traçadas.

Na oficina "Representação na Reta Real”, os alunos fizeram cálculos para identificar a posição dos números na reta real, sendo esses apresentados sob a forma de frações, raiz quadrada e também como resultado do cálculo do m.m.c. entre dois números. Cada aluno sorteou um número e, após efetuar os cálculos, o representou na reta.

\section{$5 \mathrm{O}$ processo metodológico utilizado na pesquisa}

Esta investigação teve por objetivo analisar se as oficinas desenvolvidas no PIBID promoveram a aprendizagem autorregulada das bolsistas do curso de licenciatura em Matemática, qualificando seus processos de aprender e ensinar. Formulou-se, como problema de pesquisa, a seguinte questão: as oficinas desenvolvidas no PIBID promoveram a autorregulação da aprendizagem das bolsistas do curso de licenciatura em Matemática? Para respondê-la, optou-se pela metodologia qualitativa do tipo estudo de caso. Estudo de caso, segundo Yin (2010, p. 39), “é uma investigação empírica que investiga um fenômeno 
contemporâneo em profundidade e em seu contexto da vida real, especialmente quando os limites entre o fenômeno e o contexto não estão claramente evidentes".

Inicialmente, investigou-se como foram realizadas as oficinas implementadas pelas bolsistas do curso de Matemática e, posteriormente, analisaram-se as vantagens deste trabalho, a fim de verificar qual sua contribuição para a autorregulação da aprendizagem das universitárias envolvidas. Para verificar quais impactos decorreram da intervenção realizada, foram analisados também o projeto que deu origem às oficinas e o relatório sobre o que aconteceu no percurso destas atividades. Para saber os efeitos decorrentes foram entrevistadas, um ano após o término do Projeto PIBID, três das bolsistas ${ }^{2}$ que desenvolveram as oficinas.

Optou-se pela entrevista semiestruturada por oferecer a vantagem de se desenvolver seguindo um esquema básico, porém sem a necessidade de ser aplicado rigidamente, o que permite ao pesquisador fazer as adaptações necessárias, no momento em que realiza a coleta de dados (LÜDKE; ANDRÉ, 1986).

Os procedimentos metodológicos da entrevista foram traçados seguindo um esquema básico, o qual pode ser considerado como um guia construído pela pesquisadora para facilitar a entrevista com as bolsistas. A pesquisadora organizou um quadro subdividido em três blocos de questões. No primeiro bloco, "Oficinas de Matemática desenvolvidas no PIBID”, foram elaboradas questões para estimular a entrevistada a citar alguns dados sobre o desenvolvimento das oficinas de Matemática e explicitar as contribuições para sua formação docente. O segundo bloco "Construto da aprendizagem autorregulada" objetivou investigar se as bolsistas do curso de Matemática passaram pelas três fases da autorregulação, ou seja, prévia (planejaram como construir a oficina); realização (executaram seu plano); autorreflexão (refletiram sobre as atividades realizadas, seu desempenho como professoras e as contribuições para o processo de aprendizagem dos alunos). Para compreender como a entrevistada se organizou para aplicar a oficina, foram solicitadas a descrição e a reflexão, com detalhes, sobre o contexto de aprendizagem nas oficinas e por que ele foi organizado de tal forma. O último bloco de questões "Contexto de Aprendizagens" visou proporcionar um espaço de reflexão para perceber se a entrevistada valorizou o ambiente de aprendizagem que o PIBID lhe proporcionou e se as oficinas de Matemática do PIBID provocaram mudanças em sua atuação profissional.

2 O grupo de bolsistas do curso de matemática era formado por quatro universitárias, sendo a pesquisadora uma delas, portanto as entrevistas foram realizadas com as três outras bolsistas e a pesquisadora fez um autorrelato. 
Os dados obtidos foram submetidos à técnica de análise de conteúdo. De acordo com Moraes (1999), a análise de conteúdo constitui-se em um conjunto de técnicas e instrumentos empregados para a compreensão e o processamento de dados científicos. A análise de conteúdo, como explica o autor (op. cit.), segue os seguintes passos: preparação das informações; unitarização ou transformação do conteúdo em unidades de análise; categorização, que consiste no agrupamento de unidades de significado de acordo com os diversos sentidos encontrados; descrição das principais ideias expressas; interpretação dos dados coletados à luz dos teóricos estudados.

\section{Resultados e discussões}

Conforme os dados coletados, na maioria dos depoimentos orais e escritos, emergidos tanto das entrevistas, quanto do relatório entregue ao PIBID, as bolsistas referiram que o trabalho das oficinas só deu bons resultados, porque foi realizado em parceria, colaborativamente. Damiani (2008) explicita que, na colaboração, ao trabalharem juntos, os membros de um grupo se apoiam, visando atingir objetivos comuns negociados pelo coletivo, estabelecendo relações que tendem à não hierarquização, liderança compartilhada, confiança mútua e corresponsabilidade pela condução das ações. O que a teoria explana está também contido nas falas das bolsistas, quando dizem: “este trabalho foi feito por nós...”, "nós pesquisamos..." "nós discutimos..." (Relatório das oficinas, 2009). Em raros momentos elas usaram frases como: "eu fiz..." "eu escrevi..." (Relatório das oficinas, 2009), isto evidencia a parceria, que trabalharam juntas em busca de um objetivo comum, sistematicamente estabelecido no coletivo.

Os dados analisados indicam que houve interação entre as bolsistas, que o planejamento esteve presente em toda a organização das oficinas, contribuindo para que elas desenvolvessem competências autorregulatórias para a promoção de suas aprendizagens. É interessante perceber que as fases da autorregulação da aprendizagem perpassaram todo o processo de aprendizagem das bolsistas, sem que estas soubessem que estavam demarcando suas atuações formativas e pedagógicas segundo este construto.

Conforme o ciclo autorregulatório descrito por Zimmerman (1998), verifica-se que a primeira etapa do desenvolvimento das oficinas correspondeu à fase prévia, em que o planejamento foi o centro das ações. Nesta fase, as bolsistas realizaram leituras, que lhes permitiram o aprofundamento de seus saberes sobre os conteúdos trabalhados nas oficinas. Além disso, ao planejarem as atividades, buscaram conhecer a realidade dos alunos; escolher 
os materiais didáticos adequados ao cotidiano deles; determinar o tempo de duração de cada atividade, para que se sentissem seguras ao aplicar as oficinas na escola.

Na sequência, foi contemplada a segunda fase do ciclo autorregulatório, ou seja, a etapa de execução, caracterizada pela realização das atividades planejadas. As bolsistas desenvolveram a oficina junto aos alunos, organizando estratégias, que agora se compreende como estratégias autorregulatórias em um contexto propício à aprendizagem.

A autorreflexão, terceira fase do ciclo, foi verificada na realização das oficinas. Para isso, o desempenho pessoal de cada bolsista foi minuciosamente avaliado e registrado no relatório entregue ao PIBID, tendo sido também expresso nas reflexões feitas durante a entrevista.

As bolsistas, mesmo que isso não tenha sido previsto, passaram pelas três fases do processo autorregulatório e, em seu decorrer, desenvolveram habilidades e competências que promoveram sua capacidade para autorregular o aprender e também para qualificar a forma como se propunham a ensinar.

Após as análises de conteúdo (MORAES, 1999), efetuadas sobre o projeto, o relatório das oficinas e as entrevistas, emergiram, da atuação e do desempenho das bolsistas, três categorias. Confrontou-se então o que foi feito nas oficinas com o referencial teórico, de onde surgiu o nome das categorias aqui apresentadas. Os indicadores de análise deram origem às categorias: planejamento das oficinas de Matemática realizadas em uma ação colaborativa; execução das oficinas de Matemática realizadas em uma ação colaborativa; avaliação das oficinas de Matemática realizadas em uma ação colaborativa.

Para melhor compreensão do trabalho desenvolvido pelas bolsistas, apresentam-se, no Quadro 1, as categorias com os indicadores que as definiram, as quais serão explicadas na sequência.

\begin{tabular}{|c|l|}
\hline CATEGORIAS & \multicolumn{1}{|c|}{ INDICADORES } \\
\hline $\begin{array}{c}\text { PLANEJAMENTO DAS OFICINAS DE } \\
\text { MATEMÁTICA REALIZADAS EM UMA } \\
\text { AÇÃO COLABORATIVA }\end{array}$ & $\begin{array}{l}\text { Pesquisar/conhecer o público-alvo; refletir sobre a importância de } \\
\text { trabalhar com oficinas; trabalhar em grupo; gerar um objetivo para } \\
\text { cada atividade. }\end{array}$ \\
\hline Organização & $\begin{array}{l}\text { Planejar o desenvolvimento das oficinas; utilizar estratégias } \\
\text { cognitivas para aprender os conteúdos das oficinas e decidir o } \\
\text { material didático a ser utilizado; gerir o tempo de duração de cada } \\
\text { oficina. }\end{array}$ \\
\hline Planejamento & $\begin{array}{l}\text { Compreender aspectos ligados à forma de trabalhar e ensinar os } \\
\text { conteúdos; articular teoria e prática; fomentar a linguagem } \\
\text { utilizada nas oficinas; superação da timidez. }\end{array}$ \\
\hline Tensões & \\
\hline
\end{tabular}




\begin{tabular}{|c|l|} 
Tomada de decisão & $\begin{array}{l}\text { Pedir ajuda aos colegas de graduação e aos professores do curso } \\
\text { para preparar as oficinas. }\end{array}$ \\
\hline $\begin{array}{c}\text { EXECUÇÃO DAS OFICINAS DE } \\
\text { MATEMÁTICA REALIZADAS EM UMA } \\
\text { AÇÃO COLABORATIVA }\end{array}$ & \\
\hline Contexto & $\begin{array}{l}\text { Criar um contexto propício à aprendizagem; desenvolver } \\
\text { estratégias contextuais/controle/linguagem/estratégias } \\
\text { comportamentais/autonomia/reflexão/aprendizagem }\end{array}$ \\
\hline $\begin{array}{c}\text { AVALIAÇÃO DAS OFICINAS DE } \\
\text { MATEMÁTICA REALIZADAS EM UMA }\end{array}$ & \\
AÇÃO COLABORATIVA & $\begin{array}{l}\text { Refletir sobre as oficinas desenvolvidas/ sobre os erros cometidos/ } \\
\text { sobre o desempenho dos alunos }\end{array}$ \\
\hline Reflexão/Autorreflexão &
\end{tabular}

Quadro 1 - Categorias relacionadas ao desenvolvimento das oficinas de matemática (Desenvolvido pelas pesquisadoras)

\subsection{Planejamento das oficinas de Matemática realizadas em uma ação colaborativa}

Ao analisar a maneira pela qual as oficinas de Matemática foram desenvolvidas pelas bolsistas, percebeu-se grande esforço e preocupação acerca da aprendizagem dos conteúdos de Matemática. Colaborativamente, as bolsistas realizaram longos estudos e discussões, planejaram cada atividade, escolheram materiais didáticos adequados à proposta, geriram o tempo de duração da oficina e, nesse processo, trabalharam e se esforçaram para aprender, pois o período de formação é, na realidade, um período de aprendizagem. Considerando as preocupações com o ensino oferecido na escola, as bolsistas refletiram e elegeram estratégias a serem desenvolvidas nas oficinas de Matemática.

A primeira etapa do desenvolvimento das oficinas foi o planejamento das atividades, ou seja, todas as ações preparatórias que as bolsistas fizeram, antecedendo as oficinas. Para planejarem e realizarem as estratégias de ensino, precisaram conhecer bem as possibilidades de aprendizagem dos alunos, a fim de adequarem a metodologia de ensino às suas necessidades. Assim, as oficinas foram planejadas a partir das dificuldades de aprendizagem dos alunos. Na escrita do projeto das oficinas, as bolsistas disseram: "nos empenharemos para que os alunos obtenham resultados favoráveis” (Projeto das oficinas, 2009).

As bolsistas, ao desenvolverem as oficinas, trabalharam colaborativamente, pois tinham o objetivo comum de alcançar a aprendizagem dos alunos e empenharam-se para que isso ocorresse, como evidenciam as seguintes falas retiradas das entrevistas:

Nós pensamos juntas sobre os conteúdos que seriam abordados nessas atividades, nós pesquisamos, aí sentamos e entramos em um consenso em quais atividades seriam aplicadas, na questão do tempo disponível para aplicar essas atividades, pensamos nos materiais concretos que precisavam para essas atividades, por exemplo, na oficina de frações em relação as tampinhas, número necessário de tampinhas, um número que a gente conseguisse trabalhar todos os conceitos possíveis, mas que não 
ficasse extremamente cansativo (Entrevista B1, 2011, grifos da pesquisadora).

Era um trabalho em grupo, nosso grupo era composto por quatro bolsistas, nós estudamos e elaboramos juntas essas oficinas, qual seria a melhor maneira de aplicá-las, qual seria a melhor forma de abordar esses temas, como a gente iria trabalhar com eles (Entrevista B2, 2011, grifos da pesquisadora).

Os depoimentos mostram que as bolsistas, durante o planejamento das oficinas, formaram uma equipe, na qual, ao verbalizar e explicar os pensamentos umas às outras, refletiram sobre os próprios pensamentos e sobre o pensamento das colegas. Este processo de reflexão sobre os próprios pensamentos é caracterizado como metacognição. Segundo Figueiredo (2005), a troca de ideias é uma ferramenta poderosa no que diz respeito ao desenvolvimento de competências de autorregulação. Nas discussões, como se observa nos depoimentos apresentados, as bolsistas definiram objetivos, geriram o tempo de duração de cada atividade e refletiram sobre os materiais adequados, caracterizando um processo autorregulatório.

As bolsistas, como futuras professoras, desenvolveram, durante o planejamento e a execução das tarefas, sua metacognição, o que implicou a tomada de consciência, o conhecimento e o controle dos processos cognitivos, ou seja, durante as oficinas, as bolsistas perceberam que precisavam aprender com profundidade os conteúdos trabalhados com os alunos.

Fiorentini, Souza Jr. e Melo (1998) defendem que o domínio profundo do conhecimento é fundamental para que o professor tenha autonomia intelectual para elaborar sua aula, constituindo-se mediador entre os conteúdos e os alunos. As bolsistas reconheceram que, para ensinar Matemática, necessitavam buscar um conhecimento mais profundo sobre os conteúdos a serem ensinados. Este conhecimento mais profundo é caracterizado como conhecimento declarativo. Durante o curso de Matemática, ele envolveu as experiências vivenciadas pelas bolsistas através de diferentes estratégias de aprendizagem, levando as mesmas a compreenderem os conteúdos que se propunham a ensinar nas oficinas.

As bolsistas expressaram, em seus depoimentos orais, a importância do conhecimento declarativo: "é fundamental dominar o conteúdo que tu pretendes ensinar para os alunos, assim como também é importante conhecer a realidade deles" (Entrevista B3, 2011); "nós, bolsistas, temos que ter pleno conhecimento do que se está falando, tem que ter domínio sobre aquela oficina para poder realizá-la" (Entrevista B2, 2011). O domínio a que se refere a bolsista está relacionado com o controle: conhecer bem o conteúdo, estar preparado para ensiná-lo ou mesmo para problematizar com o aluno. É preciso estar preparado para fazer o aluno pensar frente a suas inúmeras perguntas, estar preparado para esclarecer e responder as 
dúvidas que surgem no decorrer das aulas.

A partir das entrevistas evidencia-se que o planejamento das oficinas gerou tensões nas bolsistas, especificamente relacionadas a aspectos ligados à forma de trabalhar e ensinar os conteúdos. Entre tais tensões, destacam-se as geradas pela necessidade de utilizar uma linguagem clara e de vencer a timidez, o que fez com que as bolsistas, após uma conversa, decidissem pedir ajuda. Essa tomada de decisão de pedir ajuda aos professores mais experientes para a elaboração das oficinas é outro indicador de atitudes autorregulatórias. Entende-se que os sujeitos autorregulados têm consciência sobre o que precisam fazer para aprender determinado conteúdo ou se precisam desenvolver uma habilidade específica para realizar o que foi proposto. As bolsistas, ao se depararem com obstáculos, pediram ajuda às pessoas mais experientes para superá-los, como mostra o excerto da entrevista de uma delas:

O professor que nos ajudou e nos orientou, além do coordenador, trabalhava nessa área, trabalhava com oficinas, era o campo dele. Algumas vezes, nós chegamos e pedimos orientação para esse professor, ele nos ajudou e foi ele, inclusive, que nos indicou algumas leituras, das quais nós conseguimos elaborar as oficinas (Entrevista B2, 2011, grifos da pesquisadora).

No trabalho realizado, houve união entre as bolsistas e também ajuda pontual dos professores. Nessa interação, conseguiram aprender a elaborar estratégias autorregulatórias, aplicadas colaborativamente nas oficinas. Segundo Vygotsky (1994), as aprendizagens se fortalecem por meio de conquistas individuais que resultam de um processo compartilhado, isto é, da interação do sujeito com o meio social. Tal autor explica que, por meio da interação professor-aluno e aluno-aluno, o conhecimento e as formas de expressá-lo se constroem e se transformam. Através da interação com os outros se aprendem formas e procedimentos de como gestar o tempo, os objetivos e as metas, para que eles levem à internalização de novos conhecimentos (VEIGA SIMÃO, 2004). Assim, a aprendizagem, nesta investigação, revelouse como fruto de um trabalho integrado, no qual o conhecimento foi produzido de forma interacional, tendo como meio articulador a linguagem, que, conforme os escritos de Vygotsky (1994), compreende-se como a principal estratégia para autorregular a aprendizagem.

\subsection{Execução das oficinas de Matemática realizadas em uma ação colaborativa}

No desenvolvimento das oficinas, segunda etapa das atividades, as bolsistas estavam impregnadas pela ação de sistematizar tarefas para ensinar. Elas tinham a convicção de que juntas contribuiriam para a aprendizagem dos alunos, desejavam que eles compreendessem não apenas o que deveriam fazer, mas também por que e para que. Isto as motivou a 
utilizarem estratégias contextuais que se referem ao preparo ou à busca de um ambiente favorável à aprendizagem. Além de terem cuidados na organização da sala de aula para a execução das oficinas, redobraram os cuidados na revisão do material necessário para cada atividade. É relevante cuidar do espaço e do tempo, porque um ambiente propício à aprendizagem pode melhor promovê-la. As bolsistas destacaram, no relatório, o que fizeram no dia das oficinas:

Nós organizamos as classes da sala onde a oficina foi aplicada em forma de " $U$ ", $e$ o material utilizado foi colocado em uma classe no centro. Quando os alunos entraram na sala, ficaram em um primeiro momento, espantados com a organização e posteriormente demonstraram muita curiosidade em relação às atividades que seriam realizadas (Relatório das oficinas, 2009).

Infere-se, pela análise realizada, que, durante a execução das oficinas, as bolsistas trabalharam em parceria. Ao realizarem as atividades, os papéis eram alternados: em alguns momentos, uma bolsista era a protagonista na apresentação da atividade, em outros, auxiliava o grupo de alunos. A troca de papéis, segundo elas, foi muito enriquecedora para sua formação docente. Percebe-se tudo isto no excerto retirado de uma entrevista:

Enquanto uma bolsista apresentava a oficina, as outras três iam auxiliando os alunos, conforme iam surgindo as dúvidas, penso que essas mudanças de papéis foram bem importantes, porque se a mesma bolsista apresentasse todas as oficinas $e$ não auxiliasse os alunos em nenhuma, ela ia ter só uma aprendizagem, ela ia ter a visão de palestrante da oficina, ela não estaria ali participando com o aluno, construindo com ele aquela oficina. Eu tive a ação de apresentadora e a ação de construir junto com o aluno, eu acho, que, em alguns momentos, até foi mais gratificante construir junto com o aluno, do que às vezes só ir orientando a oficina (Entrevista B2, 2011, grifos da pesquisadora).

$\mathrm{Na}$ fase de execução, as bolsistas demonstraram um comportamento autorregulado a partir do uso de estratégias comportamentais, as quais se referem à consciência, ao controle do esforço, do tempo e à necessidade de ajuda. Elas deram atenção à aplicação das atividades, controlando continuamente o desenvolvimento da oficina. Quando necessário, efetuaram mudanças, por exemplo, a troca de protagonista na apresentação do trabalho ou a troca de quem explicava determinado conceito, sempre tendo em vista os objetivos que queriam alcançar, considerando a importância do autocontrole e da auto-observação em relação ao próprio desempenho na aplicação das tarefas.

\subsection{Avaliação das oficinas de Matemática realizadas em uma ação colaborativa}

A última etapa do desenvolvimento das oficinas foi a avaliação caracterizada pela análise sobre a própria atuação. As bolsistas, com a finalidade de analisar e identificar decisões tomadas, refletiram sobre elas encaminhando novas propostas de atuação. Essa fase 
surgiu em decorrência da necessidade de analisar o trabalho realizado, verificando se os objetivos tinham sido alcançados. As oficinas passaram por fases que se inter-relacionaram: a avaliação influenciou a fase prévia, que influenciou a realização e execução das atividades das oficinas, instigando reflexão sobre o que foi feito, contemplando, assim, o ciclo previsto para a autorregulação da aprendizagem (ZIMMERMAN, 1998). Através da investigação realizada, notou-se que essas reflexões ajudaram e estimularam as bolsistas a analisarem como tinham planejado e desenvolvido as oficinas, considerando também seu desempenho na apresentação das atividades, a reação dos alunos, as perguntas que emergiram das oficinas, as dificuldades encontradas, os avanços revelados. É provável que a avaliação realizada tenha estimulado a correção de estratégias utilizadas para aprender e ensinar os conteúdos presentes nas oficinas, que tenha promovido a percepção de autoeficácia, quando as bolsistas refletiram sobre o trabalho desenvolvido e se deram conta de sua importância para a aprendizagem dos alunos.

Percebeu-se, pelas entrevistas, que, nessa etapa de avaliação, as bolsistas refletiram sobre o desenvolvimento das oficinas, verificando eventuais discrepâncias e buscaram estratégias de motivação, que envolveram crenças pessoais. Diante do valor que atribuíram às oficinas, elas se esforçaram para corrigir os erros cometidos, a fim de atingir os objetivos propostos. Uma das bolsistas fez, durante a entrevista, um comentário bastante importante sobre a avaliação das oficinas:

(...) na avaliação eu pude ver os meus erros (...) acho que a avaliação, foi uma aprendizagem tão grande quanto a escrita e a execução, porque depois que você escreveu e vivenciou a aplicação da oficina, na hora da avaliação você parou e analisou o que aconteceu (Entrevista B2, 2011, grifos da pesquisadora).

Como mostra este excerto, a bolsista refletiu sobre o que fez e demonstrou ter percebido seus erros. O erro, segundo Boruchovitch (2004), deve ser considerado como uma oportunidade de aprendizagem, possibilitando revisar o trabalho para, então, alcançar o objetivo estabelecido. Através da reflexão feita pela bolsista, percebe-se uma grande preocupação com os erros, o que sugere haver constante busca de análise e aperfeiçoamento do desempenho pessoal.

$\mathrm{Na}$ entrevista, algumas bolsistas assim se manifestaram: "tínhamos algumas dúvidas e inquietações em relação à prática docente que conseguimos minimizar dentro do Projeto PIBID, com a aplicação dessa oficina” (Entrevista, 2011). As bolsistas perceberam, portanto, que ensinar e aprender dependem do esforço do professor, na medida em que buscaram a promoção de estratégias, que impulsionaram tanto a compreensão de alguns conteúdos matemáticos como o empenho e o envolvimento do aluno como sujeito ativo no processo de aprendizagem. 


\section{Considerações finais}

O processo de autorregulação da aprendizagem não ocorreu de um dia para outro. Ele se desenvolveu durante as atividades, as quais exigiram a adoção de estratégias autorregulatórias de aprendizagem. Para a realização das oficinas aqui relatadas, as bolsistas tiveram que se envolver intensamente com as atividades e as estratégias propostas, redobrando a atenção, a participação, o envolvimento, o desejo de aprender para ensinar, definindo metas e objetivos a serem atingidos. As bolsistas do curso de Matemática, futuras professoras, integravam o PIBID, o qual lhes proporcionou um espaço para aprenderem e construírem experiências profissionais relacionadas à docência. Elas refletiram sobre as atividades realizadas e buscaram novas metodologias que levassem os alunos a utilizarem estratégias e a se motivarem para aprender Matemática. Os dados coletados evidenciam que as bolsistas, por meio de ações colaborativas e do uso de estratégias de aprendizagem, adquiriram competências autorregulatórias, as quais contribuíram para o desenvolvimento das oficinas. Destaca-se, em especial, o investimento feito durante o planejamento, a execução e a avaliação das oficinas de Matemática. Para a realização das oficinas, elas foram instadas a aprofundar estudos teóricos, organizar materiais a serem utilizados nas atividades previstas, dialogar, compartilhar experiências, ajudar-se mutuamente.

Nesta pesquisa, observou-se que o Projeto PIBID ofereceu um contexto propício à aprendizagem, possibilitando às bolsistas utilizarem estratégias autorregulatórias que qualificaram seus processos de aprender e ensinar. O PIBID foi um espaço de aprendizagens conjuntas, entre bolsistas e alunos, quando todos se empenharam na consecução de um objetivo comum.

\section{Referências}

BORUCHOVITCH, E. A Auto-regulação da aprendizagem e a escolarização inicial. In: BORUCHOVITCH, E.; BZUNECK, J. A. (Orgs.) Aprendizagem: processos psicológicos e o contexto social na escola. Petrópolis, RJ: Vozes, 2004. p. 55 - 88.

D’AMBRosiO, B. S. Como ensinar Matemática Hoje? Temas e Debates. SBEM. Brasília, v. 2, n. 2, p. 15-19, Abr. 1989.

D’AMBROSIO, U. Etnomatemática: elo entre as tradições e a modernidade. Belo Horizonte: Autêntica, 2005.

DAMIANI, M. F. Entendendo o ensino colaborativo em educação e revelando seus benefícios. Revista Educar. Curitiba, n. 31, p. 213-230, Abr. 2008. 
FIGUEIREDO, F. J. C. Como ajudar os alunos a estudar e a pensar? Auto-regulação da aprendizagem. Educação, Ciência e Tecnologia. p. 233-258, 2005.

FIORENTINI, D.; SOUZA JR., A. J.; MELO, G. F. A. de. Saberes docentes: um desafio para acadêmicos e práticos. In: GERALDI, C. M. G.; FIORENTINI, D.; PEREIRA, E. M. (Org.). Cartografias do Trabalho Docente. Campinas: Mercado de Letras, 1998. p. 307-350.

FLAVELL, J. H. Metacognition and Cognitive Monitoring. American Psychologist, n. 34, p. 9061011, 1979.

LOPES DA SILVA, A.; SÁ, I. Saber Estudar e Estudar para Saber. Porto: Porto Editora, 1993.

LOPES DA SILVA, A. A auto-regulação na aprendizagem: a demarcação de um campo de estudo e de intervenção. In: LOPES DA SILVA, A.; DUARTE, A. M.; SÁ, I.; VEIGA SIMÃO, A. M. (Orgs.) Aprendizagem Auto-regulada pelo Estudante: perspectivas psicológicas e educacionais. Porto: Porto Ed., 2004. p. 17-39.

LÜDKE, M.; ANDRÉ, M. E. D. A. Pesquisa em Educação: abordagens qualitativas. São Paulo: EPU, 1986.

MORAES, R. Análise de Conteúdo. Revista Educação, Porto Alegre: EDIPUCRS, v. 22, n. 37, p.735, Nov. 1999.

OLIVEIRA, S. A. de. O lúdico com motivação nas aulas de Matemática. Jornal Mundo Jovem. Jun. 2007. P. 5 - 5. Disponível em: <http://www.mundojovem.com.br/projetos-pedagogicos/projeto-ludicomotivacao-aulas-matematica> Acesso em: 18 Ago. 2011.

PINTRICH, P. R. The role of goal orientation in self-regulated learning. In: BOEKAERTS, M.; PINTRICH, P. R.; ZEIDNER, M. (Ed.). Handbook of self-regulation. New York: Academic Press, 2000, p. 452-502.

ROSA, P. R. S. (Org.). Caderno de Resumos. In: I Encontro Institucional do PIBID UFMS. Campo Grande, 2010, p. 1-264.

ROSÁRIO, P. S. L. Estudar o Estudar: (des)venturas do Testas. Portugal: Porto Editora, 2004.

ROSÁRIO, P. S. L. MOURÃO, R.; SALAGADO, A.; RODRIGUES, A.; SILVA, C.; MARQUES, C.; AMORIM, L; MACHADO, S.; PIENDA, J.; PINA, F. Trabalhar e estudar sob a lente dos processos e estratégias de auto-regulação da aprendizagem. Psicologia, Educação e Cultura. vol. X, n.1, 2006, p. $77-88$.

ROSÁRIO, P.; NÚÑEZ, J. C.; GONZÁLEZ-PIENDA, J. Comprometer-se com o estudar na Universidade: cartas do Gervásio ao seu umbigo. Coimbra: Edições Almedina, S.A, 2006a.

ROSÁRIO, P. et al. Auto-regular o aprender que espreita nas salas de aula. In: ABRAHÃO. M. H. M. B. (Org.). Professores e Alunos: aprendizagens significativas em comunidades de prática educativa. Porto Alegre: EDIPUCRS, 2008. p.115-132.

SOUZA, C. F.; FERREIRA, D. A.; NETTO, G. F.; ROSA, I. C. P.; FERREIRA, R. G.; MELO, R. E. B. A Relação entre Universidade, Escola e Comunidade através das ações do PIBID. In: SIMPÓSIO DE MATEMÁTICA E MATEMÁTICA INDUSTRIAL, 2., 2010, Goiás. Anais... Goiás, 2010, p. 58-64.

VEIGA SIMÃO, A. M. Aprendizagem Estratégica: uma aposta na auto-regulação. Lisboa, Portugal: Editora Ministério da Educação, 2002. 
VEIGA SIMÃO, A. M. O conhecimento estratégico e a auto-regulação da aprendizagem: implicações em contexto escolar. In: LOPES DA SILVA, A.; DUARTE, A.; SÁ, I.; VEIGA SIMÃO, A. M.

Aprendizagem Auto-regulada pelo Estudante: perspectivas psicológicas e educacionais. Porto Editora: Porto, 2004. p. 77-87.

VEIGA SIMÃO, A. M. Integrar os princípios da aprendizagem estratégica no processo formativo dos professores. In: LOPES DA SILVA, A.; DUARTE, A.; SÁ, I.; VEIGA SIMÃO, A. M. Aprendizagem Auto-regulada pelo Estudante: perspectivas psicológicas e educacionais. Porto Editora: Porto, 2004a. p. 95-106.

VEIGA SIMÃO, A. M. Auto-regulação da Aprendizagem: um desafio para a formação de professores. In: BIZARRO, R.; BRAGA, F. (Org.). Formação de Professores de Línguas Estrangeiras: reflexões, estudos e experiências. Porto: Porto Ed., 2006. p. 192-206.

VEIGA SIMÃO, A. M. Reforçar o valor regulador, formativo e formador das avaliações das aprendizagens. In: ALVES, M. P.; MACHADO, E. A. (Org.). Avaliação com Sentidos(s): contributos e questionamentos. Santo Tirso, Portugal: De facto Editores, 2008. p. 17-39.

VYGOTSKY, L. S. A Formação Social da Mente. São Paulo: Martins Fontes, 1994.

YIN, R. K. Estudo de Caso: planejamento e métodos. Porto Alegre: Bookman, 2010.

ZIMMERMAN, B. J. Developing self-fulfilling cycles of academic regulation: an analysis of exemplary instructional models, In: SKUNK, D.; ZIMMERMAN, B. J. (Org.). Self-regulated Learning: from teaching to self-reflective practice. New York: The Guilford Press, 1998. p. 1-19.

ZIMMERMAN, B. J. Attaining self-regulation: a social cognitive perspective. In: BOEKAERTS, M.; PINTRICH, P.; ZEIDNER, M. (Ed.). Hanbook of Self-regulation. New York: Academic Press, 2000. p. 13-39.

ZIMMERMAN, B. J. Achieving self-regulation. In: PAJARES, F.; URDAN, T. (Eds). Adolescence and Education, Volume 2: Academic motivation of adolescents. Greenwich, CT: Information Age Publishing, 2002. p. 1-27. 